\title{
OS DESAFIOS DA EDUCAÇÃo QUILOMBOLA E O PROTAGONISMO DOS MOVIMENTOS SOCIAIS: EXPERIÊNCIAS NA COMUNIDADE COLÔNIA DO PAIOL - BIAS FORTES (MG)
}

\author{
THE CHALLENGES OF QUILOMBOLA EDUCATION AND THE PROTAGONISM \\ of SOCIAL MOVEMENTS: EXPERIENCES IN THE PAIOL Colony COMMUNiTY - \\ BIAS FORTES (MG)
}

\begin{abstract}
Ramofly Bicalho
Docente na UFRRJ - Universidade Federal Rural do Rio de Janeiro. Lotado no Departamento de Educação do Campo, Movimentos Sociais e Diversidade. Atua na Licenciatura em Educação do Campo, no PPGEA - Programa de Pós-Graduação em Educação Agrícola e no PPGEduc - Programa de Pós-Graduação em Educação, Contextos Contemporâneos e Demandas Populares. Seropédica, RJ - Brasil ramofly@gmail.com

Guilherme Goretti Rodrigues Doutorando em Educação pela Universidade Federal Rural do Rio de Janeiro Seropédica, RJ - Brasil guilhermegoretti.geografia@gmail.com
\end{abstract}

Resumo: A Educação Quilombola demarca a luta das comunidades quilombolas pelo reconhecimento do Estado e da sociedade enquanto sujeitos de direitos, bem como no avanço para a superação da opressão e da expropriação material-simbólica a que foram submetidas historicamente. Após a aprovação das Diretrizes Curriculares Nacionais para a Educação Escolar Quilombola, em 2012, diversos são os desafios para a sua implementação em realidades concretas, tornando-se necessário desvelar como as comunidades quilombolas, por meio da organização coletiva, vêm encaminhando e articulando a pauta sobre educação quilombola. Este artigo tem por objetivo refletir nos desdobramentos da aprovação das diretrizes educacionais específicas para os quilombos, tomando como análise central as experiências em curso, individuais e coletivas, da comunidade quilombola Colônia do Paiol, localizada no município de Bias Fortes, na região da Zona da Mata Mineira.

Palavras-chave: Quilombo. Educação Quilombola. Movimentos sociais.

Abstract: The Quilombola Education delimits the quilombola's communities fight for State and Society recognition as subjects of rights, and also the advance for overcoming oppression and material-symbolic expropriation to which they were historically submitted. After the approval of the National Curriculum Guidelines for Quilombola School Education, in 2012, many are the challenges for its implementation in concrete realities, making it necessary to unveil how the quilombola's commuties, through collective organization, have been forwarding and articulating the schedule about quilombola's education. This article has as its goal to reflect on the outspreads of the approval of specific educational guidelines for quilombos, taking for its central analysis the ongoing experiences, individual and collective, of the quilombola community Colônia do Paiol, located in the city of Bias Fortes, in the Zona da Mata Mineira.

Keywords: Quilombo. Quilombola Education. Social movements. 


\section{Introdução}

$\mathrm{N}$ ossas contribuições acerca dos desdobramentos da educação quilombola partem do processo de redemocratização brasileira no ano de 1988, pois é nesse contexto histórico, social e político que o Estado reconhece sua dívida para com as comunidades quilombolas no que se refere à questão do território.

Trata-se de um recorte temporal, afinal, é preciso reconhecer que as disputas políticas e educacionais — em instituições escolares e não escolares - se deram desde o período colonial, tanto na difusão dos valores civilizatórios europeus de controle material (dos recursos naturais, da mão de obra escrava e das terras) e subjetivo (da classificação racial, inferiorizando a população negra; e a norma legalista que tratava a formação dos quilombos como perigoso para a ordem social colonial-escravista), quanto das resistências das comunidades quilombolas, criando estratégias de negociação, articulação e conquista dentro da opressão a que eram submetidos.

A principal conquista das comunidades quilombolas na Constituição Federal de 1988 diz respeito ao reconhecimento e à titulação destes territórios por parte do Estado. Está expresso no art. $68^{\circ}$ do Ato das Disposições Constitucionais Transitórias (ADCT) que "aos remanescentes das comunidades dos quilombolas que estejam ocupando suas terras é reconhecida a propriedade definitiva, devendo o Estado emitir-lhes os títulos respectivos".

Entretanto, o art. $68^{\circ}$ do ADCT deve ser analisado sobre dois aspectos centrais. O primeiro deles trata-se da condensação de uma luta política que marca a emergência e rearticulação dos movimentos sociais populares após a ditadura militar. Autores como Arruti (2008) e Gomes (2017) convergem a respeito da participação e atuação do Movimento Negro Unificado (MNU)ii, fundado em 1979, nas discussões a respeito da luta contra o racismo e nas ações no âmbito da sociedade civil que buscavam a ressemantização do termo quilombo, afastando-se da ideia pejorativa de fuga e isolamento para aproximar-se de uma concepção que entende quilombo a partir da sua existência étnica no presente, que ressignifica seu modo de vida expresso pelos laços de solidariedade, ancestralidade, memória coletiva, oralidade e demais elementos que conformam a relação material-simbólica dos quilombos.

O segundo aspecto refere-se à redação incorporada pelo art. $68^{\circ}$ do ADCT, que apresentou deficiências quanto à definição do que seria o termo "remanescente", dificultando o processo de reconhecimento das comunidades quilombolas. A partir dessa imprecisão que surgiram tentativas de traçar mecanismos e procedimentos para regulamentação, identificação e titulação dos territórios quilombolas.

A principal tentativa deste período ocorreu durante o governo de FHC, expressando, entretanto, uma dramática situação: o Decreto presidencial n 3.912, de 10 de setembro de 2001, estabelecia que somente poderia ser reconhecida a titulação definitiva às comunidades que ocupavam suas terras de 13 de maio de 1888 até a Constituição de 1988. De acordo com Arruti (2008), o Decreto ainda traçava como prazo 
máximo para regularização do território quilombola o mesmo ano da promulgação da lei (2001). Ou seja, na prática isso significava restringir o direito social e territorial legítimo dos quilombos.

Somente no Decreto $n^{\circ} 4.887$, de 20 de novembro de 2003, no início do governo Lula - que revogou o Decreto n³.912 expedido pelo governo FHC, com ampla participação e luta dos movimentos sociais quilombolas, movimento negro, academia e setores da sociedade civil —, que se chega ao conceito de quilombo como: "grupos étnico-raciais, segundo critérios de autoatribuição, com trajetória histórica própria, dotados de relações territoriais específicas, com presunção da ancestralidade negra relacionada com a resistência à opressão histórica sofrida.” (BRASIL, 2003).

O critério da autoatribuição é essencial, pois permite que a própria comunidade defina os elementos simbólico-materiais considerados relevantes para o grupo, configurando a sua identidade quilombola.

É a partir desse Decreto que o Instituto Nacional de Colonização e Reforma Agrária (INCRA) que se estabelece as políticas de demarcação e titulação do território quilombola, destacando, também, a importância prévia da Fundação Cultural Palmares (FCP) na emissão dos certificados e mapeamento das comunidades quilombolas.

Mesmo com essas políticas instituídas no Estado, as ameaças e os conflitos estão colocados permanentemente. Tal como se observa ao longo do processo histórico de formação social e territorial do Brasil, a questão agrária ainda revela as faces desiguais e violentas que estruturam a nossa sociedade e o Estado.

O projeto e política nacional de desenvolvimento, que privilegia a classe ruralista e seus grandes empreendimentos (agronegócio, mineração, etc.), é a base para a exclusão e as injustiças socioambientais no campo. Desencadeia conflitos sociais e mortes, expulsa camponeses, quilombolas e indígenas de suas terras, assim como coloca em risco a biodiversidade, a flora e a fauna, os rios e as nascentes.

Por outro lado, os movimentos populares do campo, homens e mulheres que vivenciam cotidianamente as injustiças socioambientais, e produzem suas estratégias de resistência e existência, se articulam e lutam por um novo projeto de sociedade e de democracia. O campo para quilombolas, indígenas e camponeses não é lugar de morte, mas de vida, por ser uma das "matrizes formadoras dos seres humanos, na totalidade de sua condição biológica, corpórea, cultural e identitária” (ARROYO, 2014, p.209).

É a partir desses projetos antagônicos e conflitantes que nos últimos anos presenciamos uma série de retrocessos sociais, que se intensificaram após o processo de impeachment da presidenta Dilma Rousseff, em 2016. A posse do não eleito Michel Temer, apoiada pelos setores mais conservadores e reacionários do congresso nacional, deu início a uma série de ações que ameaçam os territórios quilombolas.

Como exemplo, podemos citar extinção de importantes ministérios e a consequente perda da autonomia na aplicação de recursos, como é caso do Ministério do Desenvolvimento Agrário (MDA) por meio do Decreto ${ }^{\circ} 8865$, de 29 de setembro de 2016, que transferiu as competências da Reforma Agrária do INCRA para a Casa Civil da Presidência da Repúblicaiii — e do Ministério das Mulheres, da Igualdade Racial e Direitos Humanos (MMIRDH) — por meio da Lei n¹3.341, de 29 de setembro de 2016, passando a atuar como secretaria do Ministério dos Direitos Humanos (criado pela Medida Provisória 768, 
de 2 de fevereiro de 2017) iv —, o que impacta diretamente na promoção e no investimento das políticas de combate ao racismo.

Também se enquadra no bojo dos retrocessos o julgamento da Ação Direta de Inconstitucionalidade (ADI) 3239, apresentada pelo Partido da Frente Liberal (PFL), atual Democratas (DEM). A ADI questiona os procedimentos de reconhecimento e titulação do território quilombola expressos no Decreto 4.887/2003. Entretanto, em fevereiro de 2018, o Supremo Tribunal Federal (STF) julgou improcedente a ação do PFL, resultando na derrota dos interesses da classe ruralista.

Este breve panorama acerca das políticas destinadas às comunidades quilombolas após a redemocratização, pautadas, sobretudo, no reconhecimento do território, bem como as constantes ameaças colocadas pela classe ruralista, são necessárias para a própria discussão acerca da educação quilombola, já que território e educação, para as comunidades quilombolas, não são excludentes, mas complementares.

É no território quilombola que os processos educativos também acontecem, em um ato constante de ensinar e aprender entre as gerações: nos valores de solidariedade e reciprocidade partilhados pelo grupo, no respeito à terra como sustento para as famílias, nas múltiplas formas de produção do trabalho e da existência humana, assim como na consciência de coletividade.

Se a Constituição Federal de 1988 demarcou um momento de efervescência nas reivindicações dos movimentos sociais populares - e destacamos a ação do Movimento Negro no caso das comunidades quilombolas -, com a educação não foi diferente. É importante notar como as discussões acerca de uma educação específica, que dê conta das especificidades de cada comunidade tradicional (indígena, camponesa ou quilombola), assumiu um caráter processual de ação e reflexão da realidade dentro dos movimentos sociais.

Gomes (2017) sinaliza que, até a década de 1980, a luta do Movimento Negro por educação possuía um discurso universalista. Porém, as políticas públicas de educação em caráter universal ainda não atendiam as populações negras, demandando uma discussão no interior do movimento e da militância acerca da necessidade de se pensar políticas específicas, isto é, as ações afirmativas para denunciar e estabelecer ações de combate ao racismo.

Como resultado dessa discussão e disputa no Estado, várias políticas, ainda que com desafios na sua implementação e manutenção, foram conquistadas, especialmente durante o governo do Partido dos Trabalhadores (PT): desde a criação, na estrutura do Estado, da Secretaria Nacional de Políticas de Promoção da Igualdade Racial (SEPPIR), no ano de 2003, até as políticas no âmbito da educação, tal como a Lei 10.639/03 e a Lei 11.645/08, que estabelecem a obrigatoriedade do ensino de história e cultura afrobrasileira e indígena nas redes de ensino, incluindo os artigos 26-A e 79-B na LDB 9.394/96; e a Lei ${ }^{\circ}$ $12.711 / 2012$, que estabelece as cotas raciais e sociais para o ingresso nas universidades e instituições federais de ensino; bem como diversas outras ações frutos das reivindicações do Movimento Negro.

É neste contexto histórico que a luta pela educação quilombola se situa, como resultado do acúmulo de discussões no movimento quilombola e em ampla disputa no Estado. A partir do momento que essas comunidades compreendem as representações inferiorizantes, de subordinação e negação de direitos ao longo da história, passando a pautar uma educação referenciada com as suas demandas, "o campo das 
representações sociais passa a ser um dos campos de disputa política, mas também pedagógica" (ARROYO, 2014, p.124).

As discussões a respeito de uma política de educação voltada para as comunidades quilombolas têm seu início no $1^{\circ}$ Seminário Nacional de Educação Quilombola em 2010, organizado pelo Ministério da Educação (MEC), através da Secretaria de Educação Continuada, Alfabetização, Diversidade e inclusão (SECADI), e com apoio da Secretaria de Políticas de Promoção da Igualdade Racial (SEPPIR). Neste evento foi aprovada uma comissão que iria assessorar a comissão especial da Câmara de Educação Básica (CEB), composta por membros da Coordenação Nacional das Comunidades Negras Rurais Quilombola (CONAQ), SECADI, Universidade Federal de Pelotas (UFPEL), SEPPIR, Secretaria de Educação Básica do Ministério da Educação (SEB/MEC) e Fundação Cultural Palmares (FCP) para a criação do textoreferência das Diretrizes Curriculares Nacionais para a Educação Escolar Quilombola, construída ao longo de 2011 por meio de três audiências nos Estados do Maranhão, Bahia e Distrito Federal (GOMES, 2013).

Em maio de 2012, durante o seminário promovido pelo Conselho Nacional de Educação (CNE), com o tema "Educação e Relações Étnico-Raciais", apresentou-se o acúmulo e o resultado das audiências, com o intuito de instituir as Diretrizes Nacionais para a Educação Escolar Quilombola, fato outorgado pela Resolução n, de 20 de novembro de 2012, que define as Diretrizes Curriculares Nacionais para a Educação Escolar Quilombola na Educação Básica. Este trabalho, de acordo com Gomes (2013), contou com 14 horas de discussão, problematização, debate e construção de consenso.

Em síntese, compreendemos que a educação escolar quilombola reconhece, legitima e recupera outras experiências de vida, nas suas específicas relações sociais, culturais e de trabalho. Além disso, propõe a valorização dos saberes e processos educativos presentes nos territórios quilombolas e os condensa em perspectivas epistemológicas e cognitivas, isto é, produzem novos conhecimentos que se expressam na organização da escola, do currículo, dos projetos e processos didático-pedagógicos.

Do mesmo modo, isso deve ser construído pela própria comunidade, em um processo participativo e democrático. Quando a comunidade assume esse protagonismo, a educação quilombola consegue ir além da escola, ou seja, atravessa a luta pelo território, na medida em que fortalece o pertencimento do sujeito com o território em que vive, elevando sua consciência para entender criticamente os processos excludentes e desiguais que estruturam a nossa sociedade.

Portanto, a questão que demarca a relação entre Estado e as políticas educacionais destinadas às comunidades quilombolas se referem à centralidade e ao protagonismo dos movimentos sociais populares, por meio de suas ações e práticas sociais e políticas. A definição e a redefinição de suas estratégias e táticas de luta e politização em cada período histórico nos ajudam a compreender um movimento que está em curso, subvertendo o poder hegemônico ao colocar permanentemente na arena política e social o debate e a denúncia das opressões nas dimensões de raça, gênero e classe.

É dessa subversão que emergem as experiências educativas, portadoras da transformação, na medida em que elevam a consciência individual e coletiva de forma crítica, capaz de pensar a realidade e criar condições para a sua superação. Por isso, trazer para essa análise o exemplo de uma realidade concreta significa desvelar homens e mulheres que atuam na linha de frente deste processo, inseridos em múltiplos 
contextos sociais, políticos e geográficos, mas que podem indicar e tecer caminhos cada vez mais coletivos e consistentes para as comunidades quilombolas.

Para apresentar os desdobramentos da educação quilombola na comunidade Colônia do Paiol escolhida pelos avanços observados na pauta sobre a educação - e contribuir para o debate acerca dessa temática em outras realidades, buscamos responder a algumas questões que julgamos centrais. São elas: Qual a trajetória e o processo histórico-social da comunidade? Quais as ações coletivas podem ser observadas? Como a educação quilombola começa a ser discutida na comunidade e sobre qual contexto educacional? Quais os encaminhamentos, as experiências e os resultados em curso? Quais os embates e desafios?

Tais perguntas circundam e se situam em uma reflexão que busca: (I) compreender os desafios e difusões daquilo que se instituí enquanto política educacional e a sua implementação nas comunidades quilombolas; (II) mostrar que cada comunidade possui pautas e encaminhamentos que lhe são próprias, portanto uma análise acerca dos desdobramentos da educação escolar quilombola não pode ser homogênea ou modelada, pois isso retiraria as estratégias políticas desenvolvidas cotidianamente pelos sujeitos e pelas suas organizações coletivas; (III) compreender o que essas experiências anunciam como capilaridade, isto é, emergência do que acontece em uma realidade concreta e que pode significar na aglutinação de outras comunidades, por meio da troca e diálogo coletivo entre os movimentos sociais populares.

\section{Experiências em curso na comunidade quilombola Colônia do Paiol}

A comunidade quilombola Colônia do Paiol está localizada no município de Bias Fortes-MG, distando $4 \mathrm{~km}$ do núcleo urbano. Localizada na região da Zona da Mata Mineira, a comunidade possui uma trajetória histórica, política e social que evidencia dois aspectos: partilha tanto das narrativas de opressão material, simbólica e corpórea, comum no processo de resistência das comunidades quilombolas no Brasil, bem como as estratégias de resistência e existência; quanto de um contexto geográfico específico, de necessária contextualização para entender os processos que se observam atualmente na Colônia do Paiol.

Embora reconhecendo a vasta literatura e as matrizes da historiografia, a Zona da Mata Mineira se insere na economia cafeeira ao longo do séc. XIX sob influência, dada a proximidade geográfica, do Vale do Paraíba fluminense, concomitante a uma produção voltada para a criação de animais e gêneros alimentícios (OLIVEIRA, 2010). Trata-se de um período essencial para compreender os processos sociais excludentes, já que a consolidação das fazendas voltadas para a economia cafeeira resultou na concentração de terras e no controle da mão de obra escrava por parte dos fazendeiros.

É neste contexto que surge a Colônia do Paiol, através do testamento do então fazendeiro José Ribeiro Nunes, oriundo de Bias Fortes - MG, doando parte de suas terras a seus nove ex-escravos, no ano de 1892. Contudo, por não terem acesso ao documento, a comunidade perdeu gradativamente suas terras, 
tanto pela invasão de outras fazendas no entorno, quanto por trocas (por exemplo, gêneros alimentícios por porções de terra) $)^{\mathrm{v}}$.

Este cenário não só reforçou a base latifundiária em que se formou a Zona da Mata Mineira, mas evidenciou o controle da mão de obra mesmo após a abolição da escravidão, em 1888. A redução das terras na Colônia do Paiol provocou e levou, historicamente, os moradores a estabelecerem uma relação de trabalho assalariado com os fazendeiros da região, além de uma forte migração para outras localidades (especialmente para os centros urbanos).

Esta relação marca a opressão material e simbólica, já que os moradores da Colônia do Paiol se submetiam a constantes ameaças e precarização nas condições de trabalho, o que configurou situações análogas à escravidão ao longo do século XX. Era comum o trabalho nas casas de família (dos fazendeiros) ou estabelecer o sistema da meação, isto é, uma forma de exploração em que os fazendeiros cediam suas terras para que os trabalhadores a cultivassem e colhessem, cuja produção final era dividida entre fazendeiro e trabalhador.

Se, por um lado, as expropriações pelo trabalho e pela terra estão presentes nas narrativas dos sujeitos da comunidade, por outro o imaginário social na cidade de Bias Fortes é repleto de preconceitos com relação à Colônia do Paiol. Percebe-se o racismo nas suas diversas expressões: corpórea, cultura, identitária, religiosa e ambiental, todas elas de negação dos quilombolas, como se fossem sujeitos inferiores, sem cultura e violentos.

Entretanto, são dessas experiências de violência simbólico-material que surgem as estratégias de homens e mulheres no combate a essa estrutura social racista, expropriadora e desigual. O que demarca a luta mais incisiva da comunidade se insere no final dos anos 1990 e início dos anos 2000, quando a Colônia do Paiol começa a discutir e assumir a sua identidade quilombola, resgatando memórias e oralidades, individuais e coletivas, tencionando politicamente o seu reconhecimento como remanescente quilombola através da Fundação Cultural Palmares (FCP).

Das ações e conquistas posteriores, destaca-se o reconhecimento da comunidade, em 2005, pela FCP como remanescente quilombola e a criação, em 2007, da Associação Quilombola Colônia do Paiol (AQUIPAIOL), movimento organizado pelos moradores da comunidade, que tem por objetivo construir ações coletivas que visam a atender as demandas comunitárias, acessar as políticas públicas e promover a valorização cultural da Colônia do Paiol.

Atualmente, a Associação da comunidade busca estabelecer suas ações por meio da parceria e do diálogo com outros movimentos sociais e com a academia. Destaca-se a Rede de Saberes dos Povos Quilombolas (SAPOQUI), criada em 2015, que tem por objetivo contribuir na identificação dos quilombos existentes na Zona da Mata Mineira, bem como auxiliar nas demandas comunitárias e promover a articulação das comunidades; e a Universidade Federal de Juiz de Fora (UFJF), por meio de projetos de pesquisa e extensão que visam a organização de encontros, eventos e intervenções na comunidade como forma de fortalecer socialmente a luta da Colônia do Paiol.

Das diversas pautas e encaminhamentos atuais da associação de moradores, que circundam as perspectivas de terra, cultura e trabalho, a questão da educação quilombola, enquanto diretriz curricular 
nacional, começou a ser discutida no ano de 2014, por meio da parceria com a UFJF. O diálogo surge a partir de uma vontade coletiva da associação, para que a escola, localizada na comunidade, revesse seu projeto educativo, especialmente no combate ao racismo e na valorização da identidade quilombola.

Desde a década de 1970, há na Colônia do Paiol a Escola Municipal Prefeito Joaquim Ribeiro de Paulavi, que recebe alunos da Educação Infantil e também do $1^{\circ}$ ao $5^{\circ}$ ano do Ensino Fundamental. O corpo docente é formado por seis professoras, sendo uma oriunda da comunidade (atuando com contrato temporário) e as demais tanto do município de Bias Fortes, quanto de Pedro Teixeira - MG. Para o complemento dos estudos, os alunos seguem para a Escola Estadual Cisipho Campos, localizada na cidade de Bias Fortes, que atende aos alunos do $6^{\circ}$ ao $9^{\circ}$ ano do Ensino Fundamental, Ensino Médio e Educação de Jovens e Adultos (EJA).

Mesmo com uma escola localizada em território quilombola e outra que recebe alunos de comunidade quilombola, caso da Cisipho Campos, não há uma proposta de educação — no currículo e no projeto político-pedagógico — que expresse ampla e criticamente a questão quilombola, que definimos tanto do ponto de vista de referenciar social e politicamente a luta dessas comunidades no Brasil, quanto de valorizar e reconhecer a produção de seus conhecimentos e a cultura — que envolve todos os aspectos materiais e simbólicos da existência humana.

Como desdobramento dessa realidade, identificamos, desde 2014, que na Escola Municipal Prefeito Joaquim Ribeiro de Paula, localizada na comunidade, as ações educativas de valorização quilombola acontecem muito mais pela própria iniciativa dos moradores da Colônia do Paiol do que por algo instituído no calendário ou no currículo escolar. Além disso, percebemos que os índices escolares de reprovação, desistência e transferência eram maiores para os alunos da Colônia do Paiol na Escola Estadual Cisipho Campos.

O problema central que está posto é a falta de maior reconhecimento nas escolas das práticas culturais promovidas pela comunidade e a forma com que os professores dessas escolas estão pensando e refletindo os princípios que fundamentam a diretriz curricular para a educação escolar quilombola. Neste sentido, a luta pela educação assume também a conotação política, já que a Colônia do Paiol passou a encaminhar suas demandas no âmbito da Secretaria Municipal de Educação de Bias Fortes e a cobrar da instituição de ensino superior — a UFJF — ações para a formação continuada de professores.

O diagnóstico acerca da realidade educacional na comunidade e na cidade de Bias Fortes permitiu o acúmulo de experiências de ações já realizadas e que conduzem para a implementação da educação escolar quilombola, reconhecendo que esse processo é fluído, dinâmico, entre erros e acertos.

No que se refere à formação continuada de professores, a UFJFvii promoveu o curso de extensão intitulado "Diálogos entre Escola e Saberes Tradicionais: Quilombolas, Indígenas e Camponeses" para os professores da rede municipal e estadual de Bias Fortes, com intuito de fortalecer, na teoria e na prática, as discussões a respeito da Educação Quilombola, do Campo e Indígena. Trata-se de uma ação que teve por 
esforço dialogar com uma pergunta já levantada por Arroyo (2007): qual a formação específica para ser educador (a) do campo, no nosso caso, de comunidades quilombolas?

Compreendemos que a formação docente, inicial ou continuada, para atuarem nessas realidades, deve estar em diálogo com as demandas sociais, políticas e econômicas das classes populares, isto é, ter a sensibilidade de aproximar a prática profissional à realidade e ao contexto em que está inserido. Por isso, um dos encaminhamentos na Colônia do Paiol é que se pense uma política de contratação (via concurso público) de profissionais oriundos da própria comunidade, algo previsto, inclusive, nas diretrizes curriculares para a educação escolar quilombola, justamente pela possibilidade de uma prática profissional aliada e conhecedora das demandas comunitárias.

Todavia, reconhecemos que a atual condição docente dos professores interfere também na sua prática, como a falta de plano de carreira, remuneração digna, apoio e estímulo para formação continuada, infraestrutura inadequada e materiais didático-pedagógicos; ou seja, todas as condições que refletem a política de precarização do ensino público e a falta de responsabilidade pública do Estado.

No que tange às práticas educativas promovidas pela associação da comunidade, é relevante perceber como estes movimentos repolitizam os significados sociais da escola (Arroyo, 2014). Ações como a família na escolaviii para fortalecer a identidade quilombola, o maculelê e o congado como expressão das práticas culturais, e a semana da consciência negra, nas comemorações do dia 20 de novembro - que questionam o racismo presente na sociedade brasileira — são exemplos e expressões do caráter educativo e político que a comunidade exerce. Essas trazem, em uma perspectiva ampliada, uma nova concepção para o campo curricular e pedagógico, na medida em que reivindicam o reconhecimento de suas práticas, saberes e fazeres.

Essas ações e resultados em curso permitiram que a associação da Colônia do Paiol definisse seus encaminhamentos para a implementação da educação escolar quilombola, criando suas estratégias coletivas de cobrança na Secretaria Municipal de Educação (SME).

Atualmente, está em curso a possibilidade de realização do mapeamento sociocultural na Colônia do Paiol, resgatando práticas, saberes e fazeres para a construção do Projeto político-pedagógico (PPP) da Escola Municipal Prefeito Joaquim Ribeiro de Paula. Neste documento estariam expressos os princípios que fundamentam a educação escolar quilombolaix, bem como as concepções curriculares, didáticopedagógicas (inclusive utilizando-se das experiências da formação continuada de professores já promovida) e de organização do espaço-tempo da escola, tais como calendário escolar e formas de ensino (seriado, multisseriado, alternância, ciclos, etc.).

Trata-se da construção de um documento pedagógico referenciado com as demandas comunitárias, mas que carrega, sobretudo, o sentido político, na medida em que ele é a expressão da vontade popular. Como afirmamos, a educação quilombola não segue um modelo definido, tampouco um modo específico de condução para a sua implementação. No caso da Colônia do Paiol, criar o PPP revela como os sujeitos desenvolvem suas estratégias políticas cotidianamente e como podem utilizar deste documento como elemento de reivindicação perante a Secretaria Municipal de Educação, e a responsabilidade do município 
em garantir a educação pública de qualidade e em respeito e reconhecimento das características sociais, políticas, econômicas e culturais da comunidade.

\section{Considerações finais}

As políticas educacionais destinadas aos povos e comunidades tradicionais (quilombolas, indígenas e camponeses) foram resultados da disputa permanente no Estado, como conquista dos movimentos sociais populares. Entretanto, mesmo instituídas essas políticas, inúmeros são os desafios para garantir a responsabilidade pública do Estado, comprometida com as demandas populares e reconhecendo a dívida histórica com essas comunidades.

Diante do atual contexto social e político, de desmonte da educação pública, dos direitos dos trabalhadores e trabalhadoras, das reformas que favorecem o poder político-econômico hegemônico, da emergência cada vez maior do discurso conservador e fascista, que propaga ódio e intolerância, acreditamos na potência que os movimentos sociais e a luta popular exercem para transformar e superar esta realidade. Gomes (2017), nas discussões acerca do conceito de movimento negro, nos oferece uma leitura relevante e que pode ser entendida nas análises acerca de outros movimentos populares. Mais do que entender um conceito, do que é ou do que não é:

\footnotetext{
Importa-nos compreender a potência desse movimento social e destacar as dimensões mais reveladoras do seu caráter emancipatório, reivindicativo e afirmativo, que o caracterizam como um importante ator político e como um educador de pessoas, coletivos e instituições sociais ao longo da história e percorrendo as mais diversas gerações (GOMES, 2017, p.23)
}

Desvelar os processos sociais e os projetos em disputa na Colônia do Paiol acerca da educação quilombola nos mostra como homens e mulheres vêm se colocando enquanto sujeitos históricos, portadores de uma práxis libertadora, capaz de elevar a consciência crítica, individual e coletiva, e se colocarem permanentemente no embate político.

São essas experiências moleculares, localizadas em múltiplos contextos, que devemos compartilhar, pois elas representam a chave para fortalecer as discussões em torno da educação quilombola, contribuir para uma análise crítica acerca de seus desdobramentos e revelar os caminhos e desafios a serem percorridos.

\footnotetext{
${ }^{1}$ Para essa discussão, ver Reis \& Silva (1989).

${ }^{2}$ Não dissociamos a ação do movimento quilombola com a luta do Movimento Negro. Entendemos que são movimentos complementares, dialógicos, essenciais nos encaminhamentos e demandas das lutas sociais populares no Brasil. Partimos do princípio de que o Movimento Negro compreende "as mais diversas formas de organização e articulação das negras e dos negros politicamente posicionados na luta contra o racismo e que visam à superação
} 
desse perverso fenômeno na sociedade" (GOMES, 2017, p. 23). Entretanto, a luta contra racismo não exclui as diversas outras opressões que fundam a sociedade, nas dimensões de gênero e classe.

${ }^{3}$ Em 2019, com a eleição de Jair Bolsonaro, o INCRA passa a ser competência do Ministério da Agricultura, Pecuária e Abastecimento (MAPA), por meio do Decreto n9.660, de 01/01/2019.

${ }^{4}$ Em 2019, passou-se a chamar de Ministério da Mulher, da Família e dos Direitos Humanos por meio do Decreto $\mathrm{n}^{\circ} 9.660$, de 01/01/2019.

${ }^{5}$ Tal documento comprova o direito ao território ocupado atualmente pela comunidade e, principalmente, aquelas porções invadidas pelas fazendas. Torna-se um importante elemento para que Colônia do Paiol reivindique a demarcação de suas terras junto ao Instituto Nacional de Colonização e Reforma Agrária - INCRA. Para essa discussão, ver Silva (2005) e Rodrigues (2017).

${ }^{6}$ Além da escola na Colônia do Paiol, o município de Bias Fortes-MG possuí outras seis escolas localizadas em área rural e duas em área urbana, totalizando nove escolas municipais (RODRIGUES, 2017).

${ }^{7}$ Trata-se de uma ação mediada pelos grupos de pesquisa Trabalho, Movimentos sociais populares e Educação do Campo (TRAME) da Faculdade de Educação e laboratório Kizomba Namata, do departamento de Geociências do Instituto de Ciências Humanas, ambos na Universidade Federal de Juiz de Fora.

${ }^{8}$ A família na escola é uma prática realizada a cada ano entre comunidade e professores da Escola Municipal Prefeito Joaquim Ribeiro de Paula. Trata-se de um momento de partilha, diálogo e troca, com manifestações culturais (congado ou maculelê, por exemplo) e atividades de contos e cantos, danças e teatro.

${ }^{9}$ No art. $1^{\circ}$ da Resolução ${ }^{\circ} 8$, de 20 de novembro de 2012, diz que a educação escolar quilombola deverá se fundamentar, informar e alimentar da: memória coletiva; línguas reminiscentes; marcos civilizatórios; práticas culturais; tecnologias e formas de produção do trabalho; acervos e repertórios orais; festejos, usos, tradições e demais elementos que conformam o patrimônio cultural das comunidades quilombolas de todo o país; territorialidade.

\section{Referências}

ARROYO, Miguel Gonzalez. Outros sujeitos, Outras pedagogias. 2. ed. Petrópolis: Vozes, 2014.

ARROYO, Miguel Gonzalez. Políticas de Formação de Educadores (as) do campo. Cad. Cedes, vol. 27, n. 72, pp. 157-176, mai./ago. 2007.

ARRUTI, José Maurício. Quilombos. In: PINHO, Osmundo (org.). Raça: novas perspectivas antropológicas. $2^{\mathrm{a}} \mathrm{ed}$. Salvador: ABA/Ed. da Unicamp/EDUFBA, 2008. pp. 315-350.

BRASIL. Ministério da Educação. Dispõe sobre a Resolução n ${ }^{\circ}$, de 20 de novembro de 2012 que define as Diretrizes Curriculares Nacionais para a Educação Escolar Quilombola na Educação Básica. Diário Oficial da União, Brasília, 21 de novembro de 2012, Seção 1, p. 26.

BRASIL. Decreto ${ }^{\circ} 4.887$, de 20 de novembro de 2003. Regulamenta o procedimento para identificação, reconhecimento, delimitação, demarcação e titulação das terras ocupadas por 
remanescentes das comunidades dos quilombos de que trata o art. 68 do Ato das Disposições Constitucionais Transitórias. Brasília, 2003.

REIS, João José; SILVA, Eduardo. Negociação e conflito: a resistência negra no Brasil escravista. São Paulo: Companhia das Letras, 1989.

RODRIGUES, Guilherme Goretti. A Educação Quilombola na Comunidade Colônia do Paiol - Bias Fortes (MG). 2017. 111 f. Dissertação (mestrado acadêmico) - Universidade Federal de Juiz de Fora, Faculdade de Educação, Juiz de Fora, 2017.

SILVA, Djalma Antônio da. O passeio dos quilombolas e a formação do quilombo urbano. 2005. 432 f. Tese (doutorado em Ciências Sociais) - Pontifícia Universidade Católica, São Paulo, 2005.

GOMES, Nilma Lino. O movimento negro educador: saberes construídos nas lutas por emancipação. Petrópolis: Vozes, 2017.

GOMES, Nilma Lino. Diretrizes Curriculares Nacionais para a Educação Escolar Quilombola. In: Brasil. Ministério da Educação. Diretrizes Curriculares Nacionais Gerais para a Educação Básica. Brasília: MEC, SEB, DICEI, 2013.

OLIVEIRA, Luís Eduardo de. Trabalhadores e a cidade: a formação do proletariado de Juiz de Fora e suas lutas por direito (1877-1920). Rio de Janeiro: Editora FGV, 2010.

Recebido em: 28 ago. 2018 / Aprovado em: 18 nov. 2019

Para referenciar este texto

BICALHO, Ramofly; GORETTI, Rodrigues Guilherme. Os desafios da Educação Quilombola e o protagonismo dos movimentos sociais: experiências na Comunidade Colônia do Paiol - Bias Fortes (MG). Cadernos de Pós-graduacão, São Paulo, v. 18, n. 2, p. 82-93, jul./dez. 2019. Disponível em: https://doi.org/10.5585/cpg.v18n2.10365. 